Gazi University
Journal of Science
$\mathrm{http} / /$ dergipark.gov.tr/gujs

\title{
Preparation, Characterization and Antibacterial Activity of Malva Sylvestris L. Seed Extract Containing Novel Electrospun PVA Nanofibers
}

\author{
Kubra TURAN ${ }^{1}$ (i) , Muharrem AKCAN ${ }^{2}$ (i) , Orhan Murat KALFA ${ }^{1 *}$ \\ ${ }^{1}$ Kütahya Dumlupınar University, Faculty of Art and Science, Department of Chemistry, Kütahya, Turkey \\ ${ }^{2}$ Kütahya Dumlupinar University, Faculty of Art and Science, Department of Biochemistry, Kütahya, Turkey \\ Highlights \\ - Novel PVA nanofibers containing Malva Sylvestris L. seed extract was fabricated. \\ - Electrospinning technique was used to produce nanofibers. \\ - Nanofiber diameters were 181.3 - $244.3 \mathrm{~nm}$. \\ - Nanofibers are expected to be beneficial for medical applications.
}

\begin{tabular}{l} 
Article Info \\
\hline Received:14 Sep 2020 \\
Accepted:11 Feb 2021 \\
Keywords \\
\hline Antibacterial activity \\
Biocomposites \\
Bionanofibers \\
Electrospinning \\
Malva Sylvestris L.
\end{tabular}

\begin{abstract}
Medicinal plants have been a great source for pharmaceutical agents. However, prossessing these raw sources to turn into therapeutic drugs requires highly complex technologies and expensive methods. Malva sylvestris $L$. is a commonly used vegetable in traditional and ethnoveterinary medicine because of its antimicrobial and anti-inflammatory properties. Therefore, in this study we used PVA $/ M$. sylvestris $L$. seed (MSs) extract biocomposites to produce nanofibers with electrospun technique. M. sylvestris $L$. seed extracts were prepared and divided into fractions with $20 \%$ ACN. The metabolites in MSs extract characterized by Q-TOF LC-MS. Biocomposites with different ratios of both polymer and extract were prepared for nanofiber production. Bionanofibers have been produced from these biocomposites with optimized electrospinning conditions and their morphological analysis has been performed using SEM and FTIR techniques. Nanofibers had average diameters within the range of $\sim 180-244 \mathrm{~nm}$. They were also found to have antibacterial activity against several microorganisms including Gram-negative (P.aeruginosa and E.coli) and Gram-positive (S.aureus and E.faecalis) bacteria. These newly generated bionanofibers with antibacterial properties hold great potential to be used in medical applications and food packaging.
\end{abstract}

\section{INTRODUCTION}

In the recent times, electrospun fibers have been extensively studied for various purposes by researchers from all over the world [1-5]. Electrospinning is one of the techniques to prepare fibers in which a polymer fluid can be directly converted into nano- and micro-sized scale dry fibers based on the principle of "electrostatic attraction" of charges [6]. In this technique, a polymer solution is fed from a syringe with a metal needle where high voltage is applied to create an electric field. The fiber is drastically stretched towards collector while forming a nano to micro-sized fibers that can be collected on a collector with the evaporation of the solvent $[4,7,8]$. This method produces nanofibers in the nano-range from 10 to 1000 $\mathrm{nm}$ diameter [3]. Nanofibers have been widely used in many purposes such as in biomedical applications (e.g., wound dressing material, scaffolds and drug delivery), chemical applications (e.g., catalyst, electrocromic [9], cells and batteries), defence applications (e.g. protective clothing and sensors, filters, membrane), environmental protection applications (e.g. removal of toxic wastes) [4] and membrane systems. [10] The electrospinning process demonstrates exclusive abilities for producing new natural nanofibers with controllable pore structure [11]. 
Polyvinyl alcohol (PVA) is a widely used polymer in biomedical and environmental applications. It is a water-soluble, semi-crystalline, chemically, and thermally stable, hydrophilic, fully biodegradable, nontoxic, and biocompatible polymer. PVA has been used in nanofiber production due to its wide range of application area and ease of preparation. PVA nanofibers is easily dissolved in an aqueous medium. But, to prevent its water solubility, mechanical and crosslinking agents can be used $[12,13]$.

A great variety of synthetic and natural polymers (referred to as biopolymers) or mix of these polymers are used successfully for nanofiber production. Mucilage is a gelatinous substance of plants that contains protein and polysaccharides. Biopolymers like polysaccharides can be used to solve such environmental hazards utilizing their non-biodegradability and toxicity. In nature, polysaccharides can be found in many organisms, including animal, algal, microbial or plant origin seaweeds and seeds. The polysaccharides are an important sources of nanofiber production with low cost, excellent biocompatibility and good biodegradation kinetics. The plant propagation is a natural polysaccharide source unexplained that is widely used as an additive in food or pharmaceutical preparations and exhibits significant biological characteristics such as cell growth supporter, anti-inflammatory, antibacterial, and antioxidant [14-17]. As a result, plant mucilage has become a biomaterial that scientists utilize in many fields.

Over the past 10 years, an increasing number of publications have been published on fibers that produced by electrospinning of various plant extracts with polymer supports. It is expected to increase the number of publications further in the coming years [18].

Turkey, in terms of medicinal and aromatic plants, is one of the world's richest countries. About 500 medicinal plants [19] in Turkey are utilized in traditional medicine or folk medicine practices. Many medicines used in modern medicine are obtained from plants. However, drug production is a challenging process, requiring approximately 8-13 years of research and development in very high budgets. Nanofibers developed for pharmaceutical purposes have a wide range of uses, especially biomedical applications. Nanofiber production comes to the forefront with the electrospun method thanks to the ease of production technique, affordable cost, easy preparation of new formulations, and repeatability. It can be said that electrospun nanofibers are a technology that is worth working on today and future. In this study, it is aimed to produce new bionanofibers for use in the pharmaceutical field by using the natural resources of our country.

M. sylvestris $L$. belongs to the Malvaceae plant family. It is usually known as common mallow which is an herbaceous and annual plant with superficial lobed leaves and purple flowers. It has located mainly in South-west Asia, Europe, North Africa and throughout the Mediterranean basin. Phytochemical studies of this herb have been revealed the existence of various compounds such as polyphenols, many polysaccharides, mucilage and terpenoids such as sesquiterpenes, diterpenes, monoterpenes, anthocyanins, anthocyanidines, leucoanthocyanidines, tannins, mucilagens coumarins, flavones, flavonols and essential oils [20]. It is also commonly used as a vegetable in traditional and ethnoveterinary medicine [21-23] for treatment of inflammatory processes [24-28] and respiratory, muscular, skeletal system disorders, genitourinary, and digestive, as well as mucosa injuries and skin. The mucilages are one of the main ingredients responsible for Malva's therapeutic effects, and the Malvaceae family have the most abundant mucilage accumulation.

In fact, although it is widely used for $M$. sylvestris $L$. for its astringent effects and ability to reduce tissue irritation and inflammation, several studies have been conducted on particular extracts to evaluate the plant's biological effects [20]. According to our observations, no biocomposites have been reported using plant extracts obtained from $M$. syvestris $L$. seed (MSs) in the literature yet. The aim of this study is to examine the possibility of using $M$. syvestris $L$. seed extracts as a reinforcing filler material to improve the properties of PVA-based nanofibers. 


\section{MATERIAL and METHOD}

\subsection{Apparatus and Chemicals}

Electrospinning device (nanoWEB electrospin 350) and a syringe pump (New era pump systems. Inc.) were used to obtain nanofibers. For characterization of the synthesized nanofibers, Fouriertransform infrared spectroscopy (FTIR) (Bruker-Alpha, Germany) and Scanning Electron Microscope (SEM) (FEI-Thermo Fisher Scientific, USA) were used. Ultrapure water (Merck Millipore Elix Essential 10 ultrapure system, Germany) and ultrasonic water bath (Daihan WiseClean, South Korea) were used for the preparation of all solutions in the study. The conductivity measurements were performed with SG3 (Mettler Toledo, USA) conductivity meter. The viscosity of solutions and biocomposites were measured by a First Plus model viscometer (Lamy Rheology Instruments). Liquid chromatography-mass spectrometer (LC-MS) analysis were performed with an Agilent quadrupole-time-of-flight liquid chromatography-mass spectrometer (Q-TOF LC-MS) with a Dual AJS ESI source.

The polymer solutions were prepared by dissolving PVA ( $88 \%$ hydrolyzed, average M.W. $88000 \mathrm{~g} / \mathrm{mol}$ ) (Acros Organics, Netherlands) in ultrapure water. Chemicals such as acetonitrile, formic acid and trifluoroacetic acid were used for extraction and isolation of seed extracts.

\subsection{Plant Extraction and Isolation}

M. sylvestris L. seeds were collected from Kütahya Municipality Physician Sinan Medical Plants Research Center during July 2017. Dried and grounded plant material $(10 \mathrm{~g})$ was stirred in $500 \mathrm{~mL}$ of acetonitrile/water/formic acid solution, 10:9:1 (v/v:v) overnight at room temperature. The crude extracts were filtered through a cotton wool and the liquid parts were dried with rotary evaporator and then freezedried. Initial purification was carried out using reversed phase $\mathrm{C} 18$ silica gel column. The dried, crude extract was first dissolved in solvent A ( $100 \%$ ultrapure $\mathrm{H}_{2} \mathrm{O} / 0.05 \%$ trifluoroacetic acid, v/v) and then loaded onto $\mathrm{C} 18$ material that had been activated and equilibrated with solvent $\mathrm{A}$. The fractions of the plant extract was eluted with $20 \%$ solvent $\mathrm{B}\left(90 \%\right.$ acetonitrile $/ 10 \% \mathrm{H}_{2} \mathrm{O} / 0.05 \%$ trifluoroacetic acid, $\left.\mathrm{v} / \mathrm{v} / \mathrm{v}\right)$ to separate the polar organic compounds from protein-containing fractions. The eluates were dried with rotary evaporator and then freeze-dried for LC-MS analysis and electrospinning process.

\subsection{Characterization of the Metabolites in M. Sylvestris L. Seeds Extract with LC-MS}

A $1 \mathrm{mg} / \mathrm{mL}$ solution of the plant extract was prepared in Solution A (Solution A: $\mathrm{H}_{2} \mathrm{O} / 2 \%$ acetic acid) and filtered through a $0.45 \mu \mathrm{m}$ syringe filter before injection to the Q-TOF LC-MS spectrometer. Nitrogen was used as both drying gas and nebulizer with $10 \mathrm{~L} / \mathrm{min}$ flow rate and 45 psi pressure, respectively. The temperature of the nebulizing gas was set at $350{ }^{\circ} \mathrm{C}$ and the capillary potential was set to $3500 \mathrm{~V}$. The sheath gas flow rate was $10 \mathrm{~L} / \mathrm{min}$. MS TOF analyzer fragmentor voltage was set to $165 \mathrm{~V}$ and the skimmer voltage was $65.80 \mu \mathrm{L}$ of sample was injected and the metabolites were separated on a C18 column (Poroshell 120 SB-C18, $4.6 \times 150 \mathrm{~mm}, 2.7 \mu \mathrm{m}$ particle size). A gradient of 0-80\% Solution B (Solution B: $50 \% \mathrm{CH}_{3} \mathrm{CN} / 50 \% \mathrm{H}_{2} \mathrm{O} / 0.5 \%$ acetic acid) was used as mobile phase with Solution A. A total run time of 90 min LC method was started with $10 \%$ Solution B and increased to $18 \%$ gradually over $20 \mathrm{~min}$. It was continued with increasing the \% of Solution B from $24 \%$ to $30 \%$ (15 min), 30\% isocratic (20 min), $30 \%$ to $55 \%$ (5 min), $55 \%$ to $100 \%$ ( $5 \mathrm{~min}$ ), $100 \%$ isocratic $(8 \mathrm{~min}), 100 \%$ to $10 \%$ (2 min) and finally $10 \%$ Solution $\mathrm{B}$ isocratic for $5 \mathrm{~min}$. The mass spectra were recorded in negative ion mode in the range $\mathrm{m} / \mathrm{z} 50-1000$ at an acquisition rate/time of 3 spectra/s. The spectra were analyzed with Agilent Mass Hunter Qualitative Analysis (B.06.00) software program.

\subsection{Preparation of PVA Stock Solution and Biocomposites}

PVA solutions: A $10 \mathrm{wt} \%$ PVA solution was dissolved in pure water and the mixture was stirred in an ultrasonic bath at $85{ }^{\circ} \mathrm{C}$ for 3 hours, then continued to stir at room temperature for 24 hours. Thus, a homogeneous PVA solution was obtained at a concentration of $10 \mathrm{wt} \%$ by mass. Other PVA solutions were prepared by the same method. 
PVA/MSs biocomposites: MSs extracts were weighed and transferred into a volumetric flask and mixed with PVA (10 wt \% ) solution to get $1 \mathrm{wt} \%$ of the extract. The solution was mixed in an ultrasonic bath for 4 hours to obtain a homogeneous biocomposite. It is kept in a refrigerator when it is not used to produce the nanofibers. Likewise, other biocomposites were prepared at $2 \mathrm{wt} \%$ and $4 \mathrm{wt} \%$ respectively.

Biocomposite prepared that the extract was mixed with PVA. Firstly, was determined $1 \%$ as the amount of extract added into the biocomposite, making use of existing studies in literature [29, 30]. Subsequently, instead of prepared extract (1\%) and PVA blended dispersions, the amount of mucilage was increased exponentially and new biocomposites were prepared in different proportions. In this way, more effective fibers were produced.

\subsection{Electrospinning of PVA/MSs Biocomposites}

PVA/MSs nanofibers of the $10 \mathrm{wt} \%$ PVA solution containing $M$. Slyvestris $L$. seed extracts $(0,1,2$ and 4 wt were generated by electrospinning. Firstly, PVA and PVA/MSs biocomposites were taken inside a $5 \mathrm{~mL}$ syringe tube which has a flat-end metallic $20 \mathrm{G}$ needle. A syringe pump utilized for controlling the flow rate of biocomposites and solutions. A high voltage DC power supply was used for charging the biocomposite solution and a metallic collector covered with aluminum foil for collecting nanofibers. The optimum electrospinning conditions employed for the fabrication of all nanofibers are as follows; the applied voltages are 20 and $24 \mathrm{kV}$, the rate is $2-3 \mathrm{~mL} / \mathrm{h}$, and needle to collector distance is $15 \mathrm{~cm}$. All experiments were conducted at room temperature $\left(24^{\circ} \mathrm{C}\right)$ with relative humidity of $45 \%$, and under atmospheric pressure. The parameters used are shown in Table 1. Biocomposite samples were accumulated on a rectangular collector $\left(16 \times 16 \mathrm{~cm}^{2}\right)$ covered with an aluminum foil.

\subsection{Viscosity}

The viscosity of the PVA solutions and PVA/MSs biocomposite solutions were measured by a First Plus model viscometer. The measurements were carried out five times using a MS-C19-C tube at $20-22{ }^{\circ} \mathrm{C}$.

\subsection{Electrical Conductivity of Nanofibers}

The electrical conductivities of the PVA and MSs solutions and PVA (10 wt $\%)$ :MSs(1 wt $\%)$; PVA(10 $\mathrm{wt} \%): \operatorname{MSs}(2 \mathrm{wt} \%)$; PVA(10 wt $\%): \operatorname{MSs}(4 \mathrm{wt} \%)$ biocomposites were measured by a conductivity meter (Mettler Toledo). The measurements were carried out four times at room temperature.

\subsection{Antibacterial Activity Test}

In the current study, the produced nanofibers were tested for their antibacterial activities by disc diffusion method. To determine their antibacterial activity nanofiber sheets were cut into $6 \mathrm{~mm}$ discs in diameter and were placed into live cultures of four bacteria species. The antibacterial activities were evaluated against two Gram-negative bacteria (P. aeruginosa (ATCC 27853) and E. coli (ATCC 9637)), and two Grampositive bacteria (E. faecalis (ATCC 05035) and S. aureus (ATCC 29212)). The cultures of test bacteria were preserved $4{ }^{\circ} \mathrm{C}$ and were sub-cultured prior to the antibacterial test. Bacteria were added into tubes containing 4-5 mL nutrient broth. Then, the density of these cultures was adjusted to $0.5 \mathrm{Mc}$ Farland (at $625 \mathrm{~nm}, 0.08-0.10$ absorbances) with sterile saline solution $(0.85 \% \mathrm{NaCl})$. The bacteria were inoculated in Mueller-Hinton agar. The cell suspensions containing approximately $10^{8} \mathrm{CFU} / \mathrm{mL}$ bacteria were spread on the surface with sterile swab sticks. Then, the nanofiber discs were placed on the surface of the media inoculated with the microorganisms. After the plates were incubated at $37^{\circ} \mathrm{C}$ for $24 \mathrm{~h}$ for bacterial strains, the growth inhibition zones around the disc were observed. Erythromycin $(30 \mu \mathrm{g} / \mathrm{disc})$, was used as a positive control for both for bacteria. 


\section{RESULTS AND DISCUSSION}

\subsection{Characterization of the Metabolites}

By using accutare mass Q-TOF LC-MS spectrometer, more than 20 metabolites were characterized from $M$. Sylvestris $L$. extracts as in the literature reported previously [31-34]. The molecular ion [M-H] ${ }^{-}$and MSFragment ion $\mathrm{m} / \mathrm{z}$ values were listed in Table 1 . The characterized metabolites include rutin, quercetin, 1butanamine methyl- $N$-(2-methylbutylidene, stigmasterol, campesterol. The presence of the metabolites with known antimicrobial, anti-inflammatory, chronic and inflammatory activities [21,31,35] in the extract showed that preparation of the nanofiber biocomposites containing these beneficial metabolites can be useful in pharmaceutical and supplemental food industries.

Table 1. M. Sylvestris L. seed secondary metabolites characterized with LC-MS analysis

\begin{tabular}{|c|c|c|c|c|}
\hline No & Phytochemical compound & $\begin{array}{l}\text { Molecular ion } \\
{[\mathrm{M}-\mathrm{H}]^{-}(\mathrm{m} / \mathrm{z})}\end{array}$ & $\begin{array}{l}\text { MS-Fragment } \\
\text { ions }(\mathrm{m} / \mathrm{z})\end{array}$ & Reference \\
\hline 1 & Quercetin-3-O-rutinoside & 609 & $301(100)$ & {$[32]$} \\
\hline 2 & Rutin & 609 & $300(37), 301(38)$ & [33] \\
\hline 3 & Hyperoside & 463,1 & 300,301 & [33] \\
\hline 4 & Kaempferol hexoside & 447 & $285(100)$ & [32] \\
\hline 5 & Kaempferol-3-O-glucoside & 447 & $447(100), 285(49)$ & [32] \\
\hline 7 & Stigmasterol & 412 & 412,369 & [31] \\
\hline 8 & Campesterol & 400 & $400,315,289$ & {$[31]$} \\
\hline 9 & 3-O-caffeoylquinic acid & 353 & 191,179 & [34] \\
\hline 10 & 5-O-caffeoylquinic acid & 353 & 191,179 & [34] \\
\hline 11 & Chlorogenic acid & 353 & $353,191(17)$ & [33] \\
\hline 12 & Caffeoylquinic acid & 353 & $\begin{array}{l}\text { 191(27), 179(13), } \\
135(6)\end{array}$ & {$[32]$} \\
\hline 13 & Quercetin & 301 & 179,121 & {$[33]$} \\
\hline 14 & Fisetin & 285 & 135,121 & {$[33]$} \\
\hline 15 & Quinic acid & 191 & $93(22), 85(22)$ & {$[33$} \\
\hline 16 & $\begin{array}{l}\text { 1-Naphthaienol, 1,2,3,4- } \\
\text { tetrahydro-2,5,8-trimethyl }\end{array}$ & 190 & $190,172,111$ & [31] \\
\hline 17 & $\begin{array}{l}N \text {-(2 Acetamido)imino } \\
\text { diacetic acid }\end{array}$ & 190 & $190,172,146,127$ & {$[31]$} \\
\hline 18 & Caffeic acid & 179 & $179,135(100)$ & {$[32]$} \\
\hline 19 & $\begin{array}{l}\text { 1-Butanamine methyl- } N \text { - } \\
\text { (2methylbutylidene) }\end{array}$ & 155 & $98,113,127,154$ & [31] \\
\hline 20 & Couramin & 146 & $146,103,77$ & [33] \\
\hline 21 & 4-OH Benzoic acid & 137 & 93,65 & [33] \\
\hline 22 & $\begin{array}{l}\text { 1-Propanamine, } \\
\text { 2-methyl-N-(2- } \\
\text { methylpropyldene) }\end{array}$ & 127 & 112 & {$[31]$} \\
\hline
\end{tabular}




\subsection{Parameters for Nanofiber Production}

The parameters such as solution concentration, voltage, flow rate, temperature, humidity, the distance needle to collector were first determined to produce nanofibers by electrospinning technique. The electrospinning process and parameters effect on nanofiber morphology have been previously reported [17, $18,29]$.

The electrospinning of pure MSs was not successful due to its viscosity. Therefore, the PVA solution was used as an auxiliary material to produce nanofibers from pure MSs. In order to determine the PVA concentration; 5, 8, 10, 12, $15 \mathrm{wt} \%$ polymer solutions were prepared and the nanofibers were produced. 10 wt\% PVA solution selected as an optimum PVA solution based on the viscosity effect on nanofiber diameter and it was used in later studies. The voltage, flow rate, and needle-collector distance are given in Table 2.

Table 2. The general parameters used to produce PVA/MSs nanofibers

\begin{tabular}{|l|c|c|c|}
\hline $\begin{array}{c}\text { PVA/MSs biocomposite } \\
\text { compositions }\end{array}$ & $\begin{array}{c}\text { Voltage } \\
(\mathrm{kV})\end{array}$ & $\begin{array}{c}\text { Flow rate } \\
(\mathrm{mL} / \mathrm{h})\end{array}$ & $\begin{array}{c}\text { Needle-to-collector } \\
\text { distance }(\mathrm{cm})\end{array}$ \\
\hline PVA (10 wt\%):MSs(0 wt\%) & 20 & 3.0 & 15 \\
\hline PVA (10 wt\%):MSs(1 wt\%) & 24 & 2.2 & 15 \\
\hline PVA (10 wt\%):MSs(2 wt\%) & 24 & 2.0 & 15 \\
\hline PVA (10 wt\%):MSs(4 wt\%) & 24 & 2.0 & 15 \\
\hline
\end{tabular}

Effect of solution viscosity: Viscosity increased markedly as polymer concentration increased. While the viscosity of $5 \mathrm{wt} \%$ PVA solution was $60.313 \pm 0.3373 \mathrm{mPa} . \mathrm{s}$, the viscosity of $15 \mathrm{wt} \%$ PVA was determined as $10784.20 \pm 155.26 \mathrm{mPa}$.s. Viscosity values are given in Table 3 . As the viscosity of the solution increased, nanofiber production became more difficult. The most suitable nanofiber was obtained with 10 wt\% PVA solution, and hence this polymer solution was used in further processes of the study. In addition, as the added extract concentration increased, the viscosity increased as well. Although these results [14, $36]$ are similar to the literature, some studies $[16,37]$ have compared to the contrary case too. For the same reason, PVA(10 wt $\%): M S s(2 \mathrm{wt} \%)$ was chosen as nanofiber that has optimum plant extract. Generally, it was observed that the average diameter of the electrospun nanofibers increases with viscosity [36]. When the polymer concentration in the solution increases, the fiber diameter increases with high viscosity resistance. While this situation was true for polymer solutions, a different situation was observed when the herbal ingredient was included (Table 3). Viscosity is not the only factor affecting the nanofiber diameter, so all factors should be evaluated together.

Table 3. The viscosity measurements of PVA solutions and PVA/MSs biocomposites

\begin{tabular}{|l|c|c|c|c|}
\hline \multicolumn{1}{|c|}{$\begin{array}{c}\text { Solutions and PVA/MSs } \\
\text { biocomposites }\end{array}$} & Viscosity (mPa.s $)^{\mathrm{a}}$ & Shear rate $\left(\mathrm{s}^{-1}\right)$ & $\begin{array}{c}\text { Torque } \\
(\mathrm{mN} . \mathrm{m})^{\mathrm{a}}\end{array}$ & $\begin{array}{c}\text { Temperature } \\
\left({ }^{\circ} \mathrm{C}\right)\end{array}$ \\
\hline PVA(5wt\%) & $60.313 \pm 0.373$ & 100 & $0.202 \pm 0.002$ & 20.8 \\
\hline PVA(8 wt\%) & $674.91 \pm 9.48$ & 100 & $2.144 \pm 0.19$ & 22.0 \\
\hline PVA(10 wt\%) & $1247.00 \pm 10.13$ & 100 & $3.77 \pm 0.030$ & 22.4 \\
\hline PVA(12 wt\%) & $10642.11 \pm 265.57$ & 25 & $8.02 \pm 0.19$ & 22.1 \\
\hline PVA(15 wt\%) & $15.76 \pm 0.14$ & 100 & $0.047 \pm 0.0012$ & 21.5 \\
\hline PVA(0 wt\%):MSs(1 wt\%) & $1432.88 \pm 37.54$ & 100 & $4.33 \pm 0.11$ & 21.9 \\
\hline PVA(10 wt\%):MSs(1 wt\%) & $1598.82 \pm 24.98$ & 100 & $4.83 \pm 0.080$ & 21.9 \\
\hline PVA(10 wt\%):MSs(2 wt\%) & $1686.63 \pm 40.38$ & 100 & $5.10 \pm 0.12$ & 21.8 \\
\hline PVA(10 wt\%):MSs(4 wt\%) & & & &
\end{tabular}


Contrary to the polymer concentration, humidity and temperature have no effect on the morphology of nanofibers. All experiments were conducted at room temperature $\left(24^{\circ} \mathrm{C}\right)$, with relative humidity of $45 \%$, and under atmospheric pressure. The optimum needle-to-collector distance determined as $15 \mathrm{~cm}$ and is used to produce nanofibers.

Effect of solution conductivity: The conductivity of the solution mainly affected by solvent, salt ions and the type of polymer used. When the solution conductivity increases, the load capacity of the polymer jet will increase as well. As a result, in the same electric field, the highly conductive polymer jet will be exposed to larger tensile forces and a finer fiber will be obtained. Likewise, the ions resulting from the dissolution of the salt added to the polymer solution increase the electrical charge density. As a result, the applied electrostatic field is transformed into a larger electrical force, which allows the production of thinner fibers due to greater attraction forces produced. Usually, electrospun nanofibers get shorter diameters of fibers due to high electrical conductivity $[11,14]$. In this study, the nanofiber diameters were calculated using random 13 points obtained from SEM images. When the values in Tables 4 and 5 were examined, generally diameters of the fibers decreased as the conductivity increased. Similar findings have been reported by some studies $[14,38,39]$. Although the PVA(10 wt $\%): \operatorname{MSs}(4 \mathrm{wt} \%)$ biocomposite has the highest conductivity, the fiber diameter is not the smallest. This is thought to be caused by increased viscosity due to the increased concentration of MSs.

Table 4. The diameters of PVA/MSs nanofibers

\begin{tabular}{|l|c|c|c|}
\hline PVA/MSs biocomposites & $\begin{array}{c}\text { Minimum of } \\
\text { nanofiber } \\
\text { diameter }(\mathrm{nm})\end{array}$ & $\begin{array}{c}\text { Maximum of } \\
\text { nanofiber } \\
\text { diameter }(\mathrm{nm})\end{array}$ & $\begin{array}{c}\text { Mean of nanofiber } \\
\text { diameter }(\mathrm{nm}) \pm \mathrm{SD}^{\mathrm{a}}\end{array}$ \\
\hline $\mathrm{PVA}(10 \mathrm{wt} \%): \mathrm{MSs}(0 \mathrm{wt} \%)$ & 116.0 & 250.9 & $190.9 \pm 71.9$ \\
\hline $\mathrm{PVA}(10 \mathrm{wt} \%): \mathrm{MSs}(1 \mathrm{wt} \%)$ & 90.6 & 415.6 & $244.3 \pm 87.5$ \\
\hline PVA(10 $\mathrm{wt} \%): M S s(2 \mathrm{wt} \%)$ & 108.8 & 265.0 & $181.3 \pm 52.8$ \\
\hline PVA(10 $\mathrm{wt} \%): M S s(4 \mathrm{wt} \%)$ & 108.8 & 333.2 & $184.2 \pm 64.5$ \\
\hline
\end{tabular}

${ }^{\mathrm{a}} \mathrm{N}: 13$

Table 5. Other parameters of PVA/MSs nanofibers

\begin{tabular}{|c|c|c|c|}
\hline $\begin{array}{c}\text { Solutions and PVA/MSs } \\
\text { biocomposites }\end{array}$ & $\begin{array}{c}\text { Electrical } \\
\text { Conductivity }{ }^{\mathrm{a}} \\
(\mathrm{mS} / \mathrm{cm})\end{array}$ & $\begin{array}{c}\text { Resistivity }^{\mathrm{a}} \\
(\Omega . \mathrm{cm})\end{array}$ & Salinity $(p p t)^{a}$ \\
\hline PVA(10 wt $\%): \operatorname{MSs}(0 \mathrm{wt} \%)$ & $0.28 \pm 0.01$ & $2.68 \pm 0.08$ & $0.19 \pm 0.01$ \\
\hline $\operatorname{PVA}(0 \mathrm{wt} \%): \operatorname{MSs}(1 \mathrm{wt} \%)$ & $4.55 \pm 0.09$ & $2.24 \pm 0.11$ & $2.48 \pm 0.16$ \\
\hline PVA(10 wt $\%): M S s(1 \mathrm{wt} \%)$ & $3.57 \pm 0.03$ & $2.82 \pm 0.03$ & $1.95 \pm 0.02$ \\
\hline PVA(10 wt $\%): M S s(2 w t \%)$ & $6.43 \pm 0.10$ & $1.57 \pm 0.05$ & $3.63 \pm 0.13$ \\
\hline PVA(10 wt $\%): M S s(4 \mathrm{wt} \%)$ & $7.38 \pm 0.05$ & $1.36 \pm 0.01$ & $4.17 \pm 0.14$ \\
\hline
\end{tabular}

${ }^{a} \mathrm{~N}: 4$

\subsection{Characterization of Nanofibers}

\section{FT-IR}

Fourier transform infrared (FT-IR) spectra were saved using $\mathrm{KBr}$ pellets and FT-IR spectrometer, in the range of $400-4000 \mathrm{~cm}^{-1}$. FT-IR was performed to determine whether the secondary metabolites of MSs extract were loaded on PVA/MSs biocomposite nanofibers. The FT-IR spectra of MSs (a); PVA nanofiber (b); PVA(10 wt $\%): M S s(1 \mathrm{wt} \%)$ nanofiber (c); PVA(10 wt $\%): \operatorname{MSs}(2 \mathrm{wt} \%)$ nanofiber (d) and PVA(10 wt\%):MSs(4 wt\%) nanofiber (e) are shown in Figure 1. For PVA nanofiber, the strong peaks at 850, 1098, 
$1453,1734,2937$, and $3430 \mathrm{~cm}^{-1}$ were attributed to $\mathrm{C}-\mathrm{C}, \mathrm{C}-\mathrm{O}, \mathrm{CH}-\mathrm{O}-\mathrm{H}, \mathrm{C}=\mathrm{O}, \mathrm{C}-\mathrm{H}_{2}$, and (the broad band) $\mathrm{O}-\mathrm{H}$, respectively. The band at $1450-1470 \mathrm{~cm}^{-1}$ corresponds to the vibration frequency of $\mathrm{CH}_{3}$ and the band at $1045-1055 \mathrm{~cm}^{-1}$ corresponds to the vibration frequency of CO. The band at $2850-3000 \mathrm{~cm}^{-1}$ is attributed to the vibration frequency of $\mathrm{CH}_{2}$ while the band at $3400-3600 \mathrm{~cm}^{-1}$ corresponds to the hydrogen stretching of alcohols and phenols. Not any chemical reaction between MSs and PVA was observed.

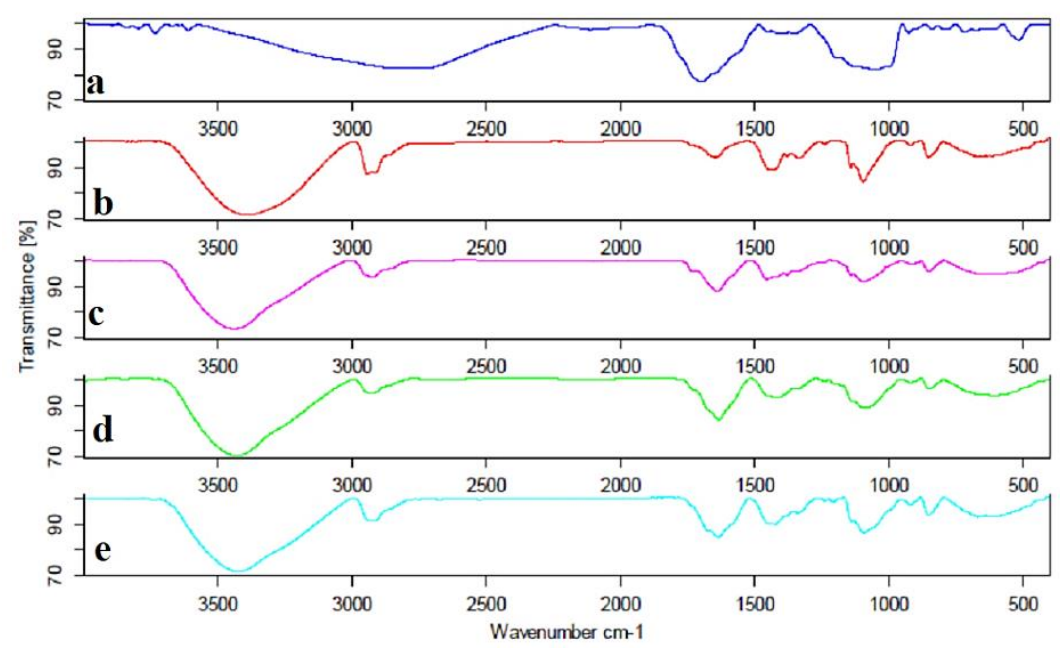

Figure 1. The FT-IR spectra of nanofibers a) MSs; b) PVA nanofiber; c) PVA(10wt\%):MSs(1 wt\%) nanofiber; d) PVA(10wt\%):MSs(2 wt\%) nanofiber and e) PVA(10wt\%):MSs(4wt\%) nanofiber

\section{SEM}

Scanning electron microscopy (SEM) was used to determine the surface morphology of the nanofibers. The SEM images of PVA nanofiber (a); PVA(10 wt $\%)$ :MSs (1 wt \%) nanofiber (b), PVA(10 wt \%):MSs(2 wt \%) nanofiber (c); PVA(10 wt $\%)$ :MSs $(4 \mathrm{wt} \%)$ nanofiber (d) are shown in Figure 2. As expected, different composition of biocomposites has a strong influence on nanofiber morphology. The nanofibers are 180$250 \mathrm{~nm}$ in diameter. Detailed diameter values shown in Table 3. Additionally, the SEM images showed that the PVA (10 wt $\%)$ :MSs (4 wt \%) biocomposite is not suitable to produce nanofiber as shown in (Figure $2 \mathrm{~d})$. As a result, the nanofibers of biocomposites containing $1 \mathrm{wt} \%$ and $2 \mathrm{wt} \%$ MSs were prepared successfully.

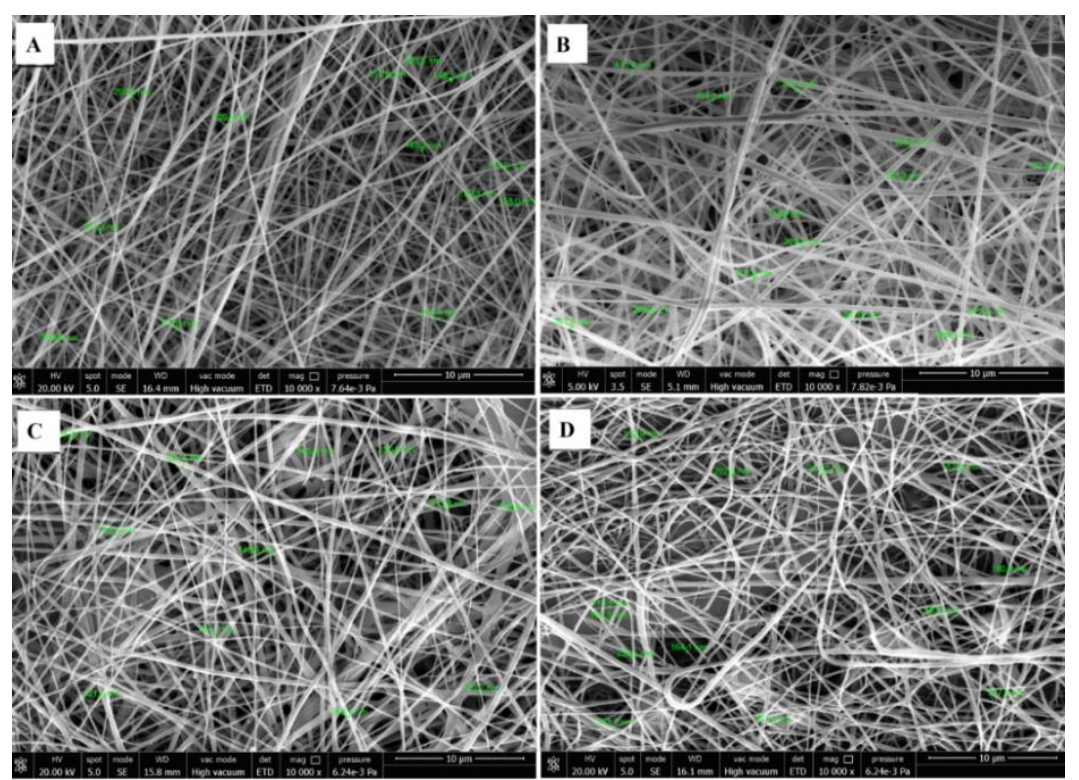

Figure 2. The SEM graphs of nanofiber from different biocomposites. Scale bar $10 \mu m$. a) PVA nanofiber; b) PVA(10 wt\%):MSs(1 wt\%) nanofiber; c) PVA(10wt\%):MSs (2wt\%) nanofiber; d) PVA(10 $w t \%): M S s(4 w t \%)$ nanofiber 


\subsection{Antibacterial Activity}

After incubation, growth inhibition zones around the nanofiber discs indicated that the extract has antibacterial effect on each microorganism. These inhibition zones were measured and shown as in Table 6. Antibiotic disc and nanofiber discs are $6 \mathrm{~mm}$ diameter. The results are given with disc size. The antibacterial activity of the extracts of MSs could be associated with metabolites such as rutin, quercetin, 1-Butanamine methyl- $N$-(2-methylbutylidene), stigmasterol and campesterol. Because, these metabolites have been reported to display antimicrobial and anti-inflammatory activities [35, 31, 21]. PVA/MSs nanofibers determined to have effective antibacterial activity against both gram-positive and gram-negative bacteria. As a result, after improving a little more antibacterial properties of these nanofibers are promising materials for antibacterial applications.

Table 6. Results of antibacterial activity test of PVA/MSs nanofibers

\begin{tabular}{|l|c|c|c|c|}
\hline \multirow{2}{*}{ Nanofibers } & \multicolumn{4}{|c|}{ Zone inhibition diameter (mm) } \\
\cline { 2 - 5 } & $\begin{array}{c}\text { Escherichia } \\
\text { coli } \\
\text { ATCC 05035 }\end{array}$ & $\begin{array}{c}\text { Pseudomonas } \\
\text { aeruginosa } \\
\text { ATCC 27853 }\end{array}$ & $\begin{array}{c}\text { Enterococcus } \\
\text { faecalis } \\
\text { ATCC 29213 }\end{array}$ & $\begin{array}{c}\text { Staphylococcus } \\
\text { aureus } \\
\text { ATCC 29212 }\end{array}$ \\
\hline $\mathrm{PVA}(10 \%)$ & 7 & 8 & 7 & 7 \\
\hline $\mathrm{PVA}(10 \%) / \mathrm{MSs}(1 \%)$ & 8 & 8 & 9 & 7 \\
\hline $\mathrm{PVA}(10 \%) / \mathrm{MSs}(2 \%)$ & 9 & 10 & 8 & 8 \\
\hline $\mathrm{PVA}(10 \%) / \mathrm{MSs}(4 \%)$ & 11 & 11 & 10 & 8 \\
\hline Erytromycin $(30 \mu \mathrm{g} / \mathrm{disc})$ & 40 & 15 & 11 & 29 \\
\hline
\end{tabular}

\section{CONCLUSION}

With this work, it has been aimed to obtain new generation biocomposite nanofiber materials by using renewable natural resources and contribute to the utilization of green technology for ecological and environmental sustainability. It also allows for the use of rich natural resources to produce valuable biomaterials that are easy to reach, work on, and not harmful to the environment. In this study, PVA nanofibers containing $M$. Slyvestris $L$. seed extracts with valuable metabolites were produced for the first time. M. Slyvestris L. seed mucilage has been obtained and used as an additive reagent for making biocomposite with $10 \mathrm{wt} \%$ PVA solution. After the optimum conditions of the electrospinning technique were determined, the characterizations of nanofibers were carried out. In addition, this plant is known to be effective against inflammation [20, 21, 22, 24-26] as it contains more than 20 metabolites such as rutin, quercetin, 1-Bütanamine methyl-N-(2-methylbutylidene, stigmasterol, campesterol. The preparation of the nanofiber biocomposites containing these beneficial metabolites can be useful in the pharmaceutical, textile and food industries. In addition, this plant is known to be effective against inflammation. As a result, by using antibacterial extracts obtained from MSs, new bionanofibers having antibacterial properties have been produced. According to the antibacterial test results, all the nanofibers produced had antibacterial effect against two Gram-positive bacteria (S. aureus and E. faecalis), two Gram-negative bacteria (E. coli and $P$. aeruginosa). Antibacterial properties are expected to provide benefits for medical applications. These newly generated bionanofibers with antibacterial properties hold great potential to be used in medical applications and food packaging.

\section{ACKNOWLEDGEMENTS}

This work was supported by Kütahya Dumlupınar University Scientific Research Projects Unit (Project no. 2018-27). We would like to thank to Prof. Dr. Tuba İÇA and her student Ecemnur SERTÇELİK for helping to antibacterial studies performed at Kütahya Dumlupınar University Zoonosis Application and Research Center. 


\section{CONFLICTS OF INTEREST}

No conflict of interest was declared by the authors.

\section{REFERENCES}

[1] Abid, S., Hussain, T., Raza, Z.A., Nazir, A., "Current applications of electrospun polymeric nanofibers in cancer therapy", Materials Science and Engineering: C, 97: 966-977, (2019).

[2] Eatemadi, A., Daraee, H., Zarghami, N., Melat Yar, H., Akbarzadeh, A., "Nanofiber: Synthesis and biomedical applications", Artificial Cells, Nanomedicine and Biotechnology, 44: 111-121, (2016).

[3] Kumar, V., Naqvi, S., Gopinath, P., Bhagyaraj, S.M., Oluwafemi, O.S., Kalarikkal, N., Thomas, S., (Eds.)"Applications of Nanomaterials", Woodhead Publishing, United Kingdom, 179-203, (2018).

[4] Thenmozhi, S., Dharmaraj, N., Kadirvelu, K., Kim, H.Y., "Electrospun nanofibers: New generation materials for advanced applications", Materials Science and Engineering: B, 217: 36-48, (2017).

[5] Wang, X., Hsiao, B.S., "Electrospun nanofiber membranes", Current Opinion in Chemical Engineering, 12: 62-81, (2016).

[6] Zdraveva, E., Fang, J., Mijovic, B., Lin, T., Bhat, G., (Ed.) "Electrospun nanofibers, in: G. Bhat (Ed.) Structure and Properties of High-Performance Fibers", Woodhead Publishing, Cambridge, USA, 267-300 (2017).

[7] Braghirolli, D.I., Steffens, D., Pranke, P., "Electrospinning for regenerative medicine: a review of the main topics", Drug Discovery Today, 19: 743-753, (2014).

[8] Wang, J., Windbergs, M., "Functional electrospun fibers for the treatment of human skin wounds", European Journal of Pharmaceutics and Biopharmaceutics, 119: 283-299, (2017).

[9] Turgut Cin, G., Nohut Maşlakcı, N., Biçer, A., Yakalı, G., Uygun Öksüz, A., "Electrochromic Properties of Electrospun Fibers Based on Bis-Thiomethylcyclohexanone Derivatives", Chemistry Select, 4: 13412-13419, (2019).

[10] Saallah, S., Naim, M.N., Mokhtar, M.N., Bakar, N.F.A., Gen, M., Lenggoro, I.W., "Preparation and Characterisation of Cyclodextrin Glucanotransferase Enzyme Immobilised in Electrospun Nanofibrous Membrane", Journal of Fiber Science and Technology, 73: 251-260, (2017).

[11] Bhardwaj, N., Kundu, S.C., "Electrospinning: a fascinating fiber fabrication technique", Biotechnology Advances, 28: 325-347, (2010).

[12] Enayati, M.S., Behzad, T., Sajkiewicz, P., Bagheri, R., Ghasemi-Mobarakeh, L., Łojkowski, W., Pahlevanneshan, Z., Ahmadi, M., "Crystallinity study of electrospun poly (vinyl alcohol) nanofibers: effect of electrospinning, filler incorporation, and heat treatment", Iranian Polymer Journal, 25(7): 647659, (2016). DOI: 10.1007/s13726-016-0455-3

[13] Miraftab, M., Saifullah, A.N., Çay, A., "Physical stabilization of electrospun poly (vinyl alcohol) nanofibers: comparative study on methanol and heat-based crosslinking", Journal of Material Science 50: 4174-4186, (2015).

[14] Fahami, A., Fathi, M., "Fabrication and characterization of novel nanofibers from cress seed mucilage for food applications", Journal of Applied Polymer Science, 135: 45811, (2018). 
[15] Jawaid, M., Swain, S., "Bionanocomposites for Packaging Applications", Springer Nature, Switzerland, (2018).

[16] Kurd, F., Fathi, M., Shekarchizadeh, H., "Basil seed mucilage as a new source for electrospinning: Production and physicochemical characterization", International Journal of Biological Macromolecules, 95: 689-695, (2017).

[17] Urena-Saborio, H., Alfaro-Viquez, E., Esquivel-Alvarado, D., Madrigal-Carballo, S., Gunasekaran, S., "Electrospun plant mucilage nanofibers as biocompatible scaffolds for cell proliferation", International Journal of Biological Macromolecules, 115: 1218-1224, (2018).

[18] Zhang, W., Ronca, S., Mele, E., "Electrospun Nanofibres Containing Antimicrobial Plant Extracts", Nanomaterials (Basel), 7, (2017).

[19] Bozyel, M.E., Merdamert Bozyel, E., Canli, K., Altuner, E.M., "Anticancer Uses of Medicinal Plants in Turkish Traditional Medicine", KSU Journal of Agriculture and Nature, 22(Suppl 2): 465-484, (2019). DOI:10.18016/ksutarimdoga.vi.550334 .

[20] Delfine, S., Marrelli, M., Conforti, F., Formisano, C., Rigano, D., Menichini, F., Senatore, F., "Variation of Malva sylvestris essential oil yield, chemical composition and biological activity in response to different environments across Southern Italy", Industrial Crops and Products, 98: 29-37, (2017).

[21] Benso, B., Franchin, M., Massarioli, A.P., Paschoal, J.A., Alencar, S.M., Franco, G.C., Rosalen, P.L., "Anti-Inflammatory, Anti-Osteoclastogenic and Antioxidant Effects of Malva sylvestris Extract and Fractions: In Vitro and In Vivo Studies", PLoS One, 11: e0162728, (2016).

[22] Hussain, L., Ikram, J., Rehman, K., Tariq, M., Ibrahim, M., Akash, M.S.H., "Hepatoprotective effects of Malva sylvestris L. against paracetamol-induced hepatotoxicity", Turkish Journal of Biology, 38: 396-402, (2014).

[23] Prudente, A.S., Loddi, A.M., Duarte, M.R., Santos, A.R., Pochapski, M.T., Pizzolatti, M.G., Hayashi, S.S., Campos, F.R., Pontarolo, R., Santos, F.A., Cabrini, D.A., Otuki, M.F., "Pre-clinical antiinflammatory aspects of a cuisine and medicinal millennial herb: Malva sylvestris L", Food and Chemical Toxicology, 58: 324-331, (2013).

[24] Ben Saad, A., Rjeibi, I., Brahmi, D., Smida, A., Ncib, S., Zouari, N., Zourgui, L., "Malva sylvestris extract protects upon lithium carbonate-induced kidney damages in male rat", Biomedicine \& Pharmacotherapy, 84: 1099-1107, (2016).

[25] Elsagh, M., Fartookzadeh, M.R., Kamalinejad, M., Anushiravani, M., Feizi, A., Behbahani, F.A., Rafiei, R., Arjmandpour, A., Adibi, P., "Efficacy of the Malva sylvestris L. flowers aqueous extract for functional constipation: A placebo-controlled trial", Complementary Therapies in Clinical Practice, 21: 105-111, (2015).

[26] Kovalik, A.C., Bisetto, P., Pochapski, M.T., Campagnoli, E.B., Pilatti, G.L., Santos, F.A., "Effects of an orabase formulation with ethanolic extract of Malva sylvestris L. in oral wound healing in rats", Journal of Medicinal Food, 17: 618-624, (2014).

[27] Rostami, H., Gharibzahedi, S.M.T., "Cellulase-assisted extraction of polysaccharides from Malva sylvestris: Process optimization and potential functionalities", International Journal of Biological Macromolecules, 101: 196-206, (2017). 
[28] Samavati, V., Manoochehrizade, A., "Polysaccharide extraction from Malva sylvestris and its antioxidant activity", International Journal of Biological Macromolecules, 60: 427-436, (2013).

[29] Santos, C., Silva, C.J., Buttel, Z., Guimaraes, R., Pereira, S.B., Tamagnini, P., Zille, A., "Preparation and characterization of polysaccharides/PVA blend nanofibrous membranes by electrospinning method", Carbohydrate Polymer, 99: 584-592, (2014). DOI: 10.1016/j.carbpol.2013.09.008

[30] Costa, L.M.M., de Olyveira, G.M., Cherian, B.M., Leão, A.L., de Souza, S.F., Ferreira, M., "Bionanocomposites from electrospun PVA/pineapple nanofibers/Stryphnodendron adstringens bark extract for medical applications", Industrial Crops and Products, 41: 198-202, (2013). DOI: 10.1016/j.indcrop.2012.04.0252.5.

[31] Al-Rubaye, A.F., Kaizal, A.F., Hameed, I.H., "Phytochemical Screening of Methanolic Leaves Extract of Malva sylvestris", International Journal of Pharmacognosy and Phytochemical Research, 9: 537$552,(2017)$.

[32] Barros, L., Dueñas, M., Carvalho, A.M., Ferreira, I.C.F.R., Santos-Buelga, C., "Characterization of phenolic compounds in flowers of wild medicinal plants from Northeastern Portugal", Food and Chemical Toxicology, 50: 1576-1582, (2012).

[33] Hasimi, N., Ertaş, A., Varhan Oral, E., Alkan, H., Boğa, M., Yılmaz, M.A., Yener, İ., Gazioğlu, I., Özaslan, C., Akdeniz, M., Kolak, U., "Chemical Profile of Malva Neglecta and Malvella Sherardiana by LC- MS/MS, GC/MS and Their Anticholinesterase, Antimicrobial and Antioxidant Properties With Aflatoxin-Contents", Marmara Pharmaceutical Journal, 21: 471-471, (2017).

[34] Navarro-Gonzalez, I., Gonzalez-Barrio, R., Garcia-Valverde, V., Bautista-Ortin, A.B., Periago, M.J., "Nutritional composition and antioxidant capacity in edible flowers: characterisation of phenolic compounds by HPLC-DAD-ESI/MSn", International Journal of Molecular Sciences, 16: 805-822, (2014).

[35] Abat, J.K., Kumar, S., Mohanty, A., "Ethnomedicinal, Phytochemical and Ethnopharmacological Aspects of Four Medicinal Plants of Malvaceae Used in Indian Traditional Medicines": A Review, Medicines (Basel), 4, (2017).

[36] Mishra, P., Gupta, P., Pruthi, V., "Cinnamaldehyde incorporated gellan/PVA electrospun nanofibers for eradicating Candida biofilm", Material Science Engineering C, 119: 111450, (2021). DOI: 10.1016/j.msec.2020.111450

[37] Ramalingam, R., Dhand, C., Leung, C.M., Ong, S.T., Annamalai, S.K., Kamruddin, M., Verma, N.K., Ramakrishna, S., Lakshminarayanan, R., Arunachalam, K.D., "Antimicrobial properties and biocompatibility of electrospun poly-epsilon-caprolactone fibrous mats containing Gymnema sylvestre leaf extract", Material Science Engineering C, 98: 503-514, (2019). DOI: 10.1016/j.msec.2018.12.135

[38] Dehcheshmeh, M.A., Fathi, M., "Production of core-shell nanofibers from zein and tragacanth for encapsulation of saffron extract", International Journal of Biological Macromolecules, 122: 272-279, (2019). DOI : 10.1016/j.ijbiomac.2018.10.176

[39] Rezaei, A., Nasirpour, A., "Encapsulation of curcumin using electrospun almond gum nanofibers: fabrication and characterization", International Journal of Food Properties, 21(1): 1608-1618, (2018). DOI : $10.1080 / 10942912.2018 .1503300$ 